\title{
Comparison of natural durability of wood by stake tests followed by survival analysis
}

\author{
Ikuo Momohara ${ }^{*} \mathbb{0}$, Haruko Sakai ${ }^{2}$, Hiroshi Kurisaki ${ }^{3}$, Wakako Ohmura ${ }^{4}$, Toshikazu Kakutani ${ }^{5}$, \\ Tokio Sekizawa ${ }^{6}$ and Yuji Imamura ${ }^{7}$
}

\begin{abstract}
The conventional stake test is widely used to evaluate wood durability. The test monitors the deterioration level observed on stakes partially inserted into the ground. The test results are conventionally expressed as the relationship between the mean deterioration level and exposure periods. Durability is compared between the stake groups based on the test results; however, there is no scientific basis for the comparison. To include a scientific basis to the conventional stake test, we applied survival analysis to it. Four stake groups were subjected to deterioration at three sites for 7 years. The deterioration levels were monitored according to the conventional procedure, and survival analysis was applied to the monitored data. The Kaplan-Meier curves plotting the survival probabilities against the exposure periods indicated that the durability of the test stakes of Japanese cedar heartwood is higher than those of Japanese cedar sapwood. However, it was also demonstrated that the durability ratio between Japanese cedar heartwood and sapwood was strongly dependent on the test sites. It was also revealed that the durability of the heartwood portion did not differ significantly among Japanese cedar, Japanese cypress, and Japanese larch. These results were verified using the modified Gehan-Wilcoxon test.
\end{abstract}

Keywords: Wood, Durability, Stake test, Field test, Survival analysis, Service life

\section{Introduction}

Wood is a material that mitigates global warming via the carbon stock, material substitution, and energy substitution effects [1-3]. The replacement of concrete/steel materials by wooden ones has led to reduced carbon dioxide emissions [4-6]. Therefore, attempts have been made to replace steel and concrete used in architecture and civil engineering with novel wooden materials such as cross-laminated, nail-laminated, and dowel-laminated timber [7-9]. In addition to increasing the volume of the carbon stock effect, trials have been conducted to prolong its lifespan by increasing the shelf life of wooden materials to reduce global warming. Hence, studies have been carried out to develop more durable wooden

\footnotetext{
*Correspondence: momohara@ffpri.affrc.go.jp

${ }^{1}$ Kansai Research Center, Forestry and Forest Products Research Institute,

Fusimiku, Kyoto 612-0855, Japan

Full list of author information is available at the end of the article
}

materials [10-15], and many methods have been proposed to evaluate them, such as laboratory decay tests $[16,17]$, stake tests [17-19], and fungus-cellar tests $[17,20]$. Among these, the stake test is a fundamental method for estimating wood durability; therefore, it has been widely adopted by many researchers. According to the International Research Group on Wood Protection (IRG), approximately 900 IRG documents related to stake tests have been released in the last two decades [21].

The stake test procedure is straightforward. Stakes are inserted into the ground up to half the stake lengths and checked visually after a certain interval. The observed stake deterioration levels are evaluated according to the criteria for each standard. Japanese Industrial Standard (JIS) K 1571 [17] defines the sound stake and broken stake deterioration levels as 0 and 5, respectively. Stakes showing deterioration levels intermediate between these values are rated between 1 and 4, depending on the stake conditions. The durability of each treatment group is
Springer Open
C The Author(s) 2021. This article is licensed under a Creative Commons Attribution 4.0 International License, which permits use, sharing, adaptation, distribution and reproduction in any medium or format, as long as you give appropriate credit to the original author(s) and the source, provide a link to the Creative Commons licence, and indicate if changes were made. The images or other third party material in this article are included in the article's Creative Commons licence, unless indicated otherwise in a credit line to the material. If material is not included in the article's Creative Commons licence and your intended use is not permitted by statutory regulation or exceeds the permitted use, you will need to obtain permission directly from the copyright holder. To view a copy of this licence, visit http://creativeco mmons.org/licenses/by/4.0/. 
compared based on the year when the mean deterioration level reaches 2.5 .

Although the stake test is an easy way to predict the wood durability in ground contact conditions, it lacks scientific precision in the data analysis process, and hence, it is impossible to compare the durability of stake groups with each other. To overcome this issue, we applied survival analysis [22] to the data obtained in the conventional test. We present the results after applying survival analysis to the stake test data samples and discuss the merits of adding survival analysis to the conventional stake test.

\section{Material and methods \\ Preparation of stakes}

Stakes of Japanese cedar (Cryptomeria japonica), Japanese cypress (Chamaecyparis obtusa), and Japanese larch (Larix kaempferi) were prepared by a preserving company. Green logs of the three species obtained from Gunma Prefecture were sawn to make planks. After the planks were dried naturally, they were sawn to prepare stakes of size $3 \times 3 \times 60 \mathrm{~cm}(\mathrm{~L})$.

\section{Test sites}

Stake tests were performed at three test sites (Table 1). The locations of the sites were obtained from maps on the Geospatial Information Authority of Japan website [23]. Weather data for the sites were determined based on the monthly weather data at Tsukuba, Nara, and Toyama-city from 2012 to 2018 on the Japan Meteorological Agency website [24]. The soil types of the Ibaraki and Nara sites were obtained from the Japan soil inventory website constructed by the National Agriculture and Food Research Organization [25]; that of the Toyama site was determined by the specifications at the construction of the field test site by the Toyama Forest Products Research Institute.

\section{Exposure to wood attacking organisms}

At the three test sites, the prepared stakes were inserted into the ground up to half the stake lengths. The abbreviations for the stakes are listed in Table 2. The stake deterioration levels were evaluated annually according

Table 1 Characteristics of the three field test sites

\begin{tabular}{llll}
\hline Name of test site & Location & & Soil type \\
\cline { 2 - 3 } & latitude & Longitude & \\
\hline Ibaraki & $36^{\circ} 2^{\prime} 08.2^{\prime \prime}$ & $140^{\circ} 6^{\prime} 01.0^{\prime \prime}$ & Andosol \\
Nara & $34^{\circ} 28^{\prime} 29.8^{\prime \prime}$ & $135^{\circ} 48^{\prime} 54.2^{\prime \prime}$ & Gleysol \\
Toyama & $36^{\circ} 42^{\prime} 20.1^{\prime \prime}$ & $137^{\circ} 6^{\prime} 01.4^{\prime \prime}$ & Sandy loam \\
\hline
\end{tabular}

Table 2 Abbreviations used for each stake group

\begin{tabular}{lllll}
\hline Species (position) & \multicolumn{2}{l}{ Name of test site } & All sites \\
\cline { 2 - 4 } & lbaraki & Nara & Toyama & \\
\hline $\begin{array}{l}\text { Japanese cedar } \\
\text { (sapwood) }\end{array}$ & Ced-S-I & Ced-S-N & Ced-S-T & Ced-S \\
$\begin{array}{l}\text { Japanese cedar } \\
\text { (heartwood) }\end{array}$ & Ced-H-I & Ced-H-N & Ced-H-T & Ced-H \\
$\begin{array}{l}\text { Japanese cypress } \\
\text { (heartwood) }\end{array}$ & Cyp-H-I & Cyp-H-N & Cyp-H-T & Cyp-H \\
$\begin{array}{l}\text { Japanese larch } \\
\text { (heartwood) }\end{array}$ & Lar-H-I & Lar-H-N & Lar-H-T & Lar-H \\
\hline
\end{tabular}

to JIS K 1571 [17] criteria (Table 3). The data obtained for 7 years were used for further analysis.

\section{Data analysis by conventional method}

Data analysis and service life determination using the conventional method was carried out in accordance with JIS K 1571 [17]. Apparent arithmetic means of the annually collected data were calculated by considering the ordinal scale as a proportional scale. The years during which the apparent mean deterioration level reached 2.5 were determined according to Eq. (1) and designated as the service life of the stake (Fig. 1):

$$
\mathrm{YSL}=\mathrm{Y} 1+(2.5-\mathrm{DL} 1) /(\mathrm{DL} 2-\mathrm{DL} 1),
$$

where YSL is the service life of the stake group, Y1 is the last year in which the mean deterioration level of the stake was below 2.5, DL1 is the mean deterioration level of the stake observed at Y1, and DL2 is the mean deterioration level of the stake observed 1 year after $\mathrm{Y} 1$.

A stake that reached a deterioration level of 5 during a certain period was considered to have a deterioration level of 5 thereafter. If a stake was lost in a certain year, mean calculation was conducted without the lost stake.

Table 3 Deterioration level criteria

\begin{tabular}{ll}
\hline $\begin{array}{l}\text { Deterioration } \\
\text { level }\end{array}$ & Conditions of stake \\
\hline 0 & $\begin{array}{l}\text { Sound } \\
1\end{array}$ \\
2 & Partially slight rot and/or termite attack \\
3 & Wholly slight rot and/or termite attack \\
4 & $\begin{array}{l}\text { Partially severe rot and/or termite attack on the } \\
\text { condition in 2 }\end{array}$ \\
5 & Wholly severe rot and/or termite attack \\
\hline
\end{tabular}




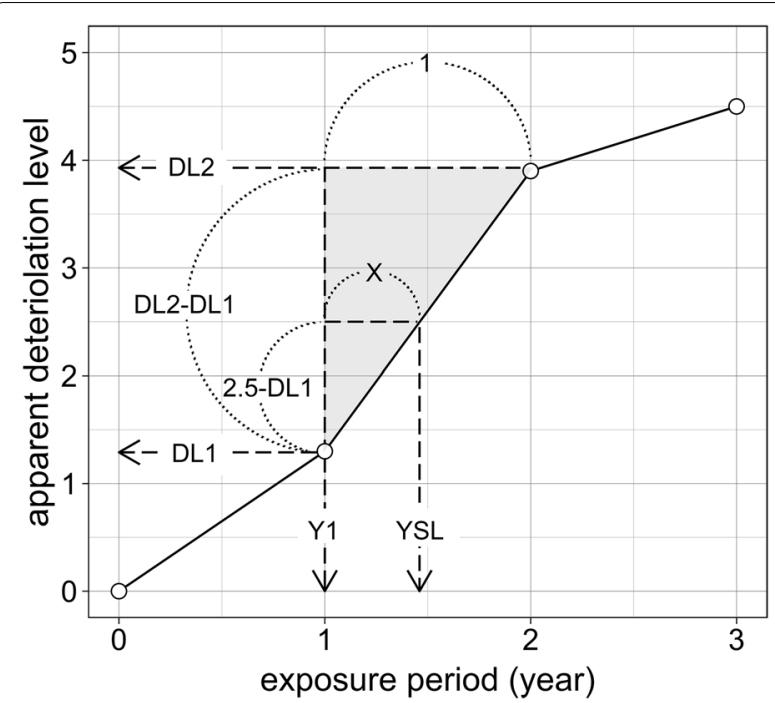

Fig. 1 Methodology for service life calculation

\section{Data analysis according to survival analysis}

The service life of the stake was designated as the year when the deterioration level of a stake reached 2.5. The service life was determined according to Eq. (1), except that the individual deterioration level of each stake was used instead of the mean deterioration level. The individual service life data were collected and used for survival analysis. Survival analysis was carried out using R software [26]. Multiple comparisons of survival curves were carried out according to the Peto \& Peto modification of the Gehan-Wilcoxon test with the Holm's $p$ adjustment method [27].

\section{Results and discussion}

\section{Characteristics of test sites}

The weather data for the test sites are shown in Fig. 2. The data showed a similarity in the monthly temperature patterns, but a difference was noted in the precipitation patterns of the three sites. Ibaraki and Nara showed higher precipitation from June to October, while Toyama had rainy and snow season from July till January.

As indicated by the soil type data (Table 1), the soil of the Nara site appeared more moist than that of the Toyama site, which appeared slightly dehydrated because of its high drainage property. In addition to the moisture conditions, the soil quality of the Toyama site was the poorest because this site was newly established in 2009 after amending with sandy-loam soil.

\section{Service life determination using the conventional method}

The field test has been adopted as a standard testing method in many countries to determine the durability of

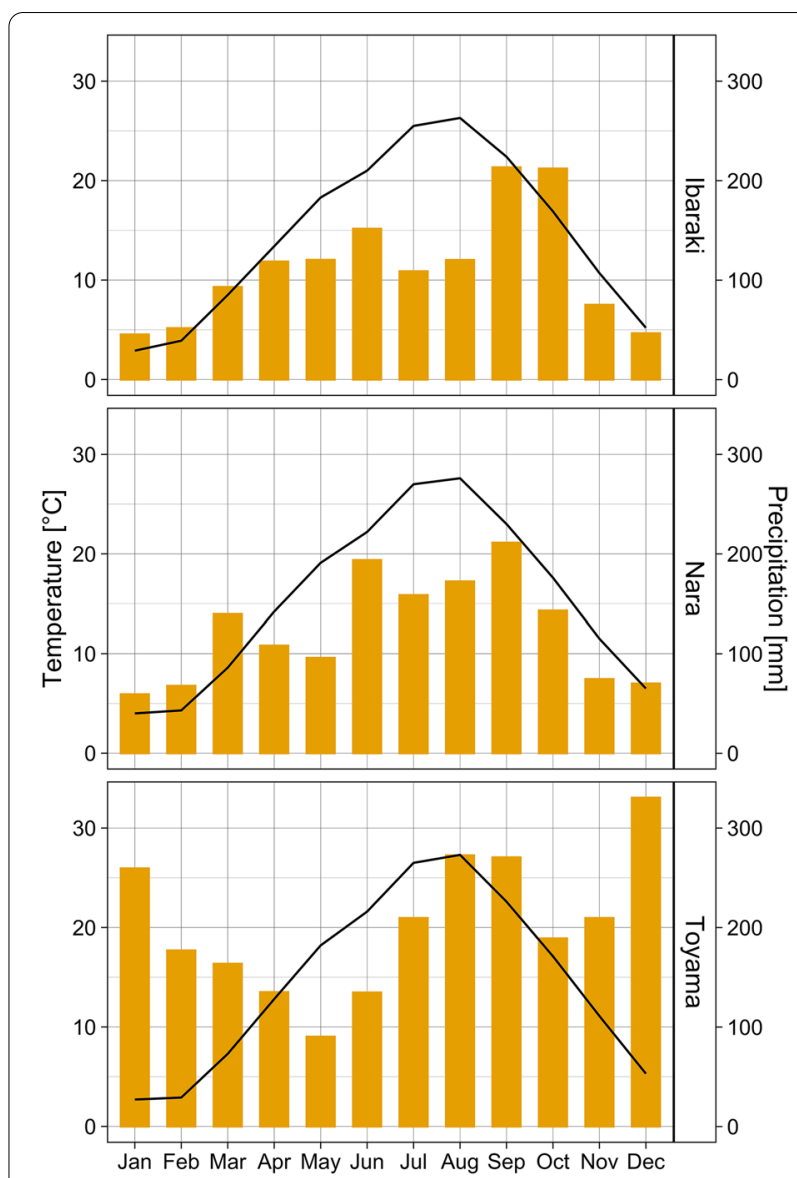

Fig. 2 Monthly temperature and precipitation data for the three test sites. - Temperature, precipitation

wood and wood products in ground contact conditions. The procedure of the field test in JIS K 1571 [17] is as follows: stakes inserted into the ground up to half the stake lengths are first inspected after a certain period by visual observation. Second, the deterioration levels observed on the stakes are checked and designated as per six deterioration levels, between 0 (sound) and 5 (collapse). Finally, the service life of the stakes is determined by plotting mean deterioration levels against exposure periods.

Figure 3 shows an example of service life determination by conventional calculation using cedar stakes data obtained from the three sites. Close and open circles indicate the mean deterioration levels of Ced-S and Ced-H observed during each exposure period. As shown in the figure, the mean deterioration levels of Ced-S and Ced-H increased with an increase in the exposure period and reached 2.5 in approximately 2.0 and 2.7 years, respectively. Therefore, the service lives of Ced-S and Ced-H were 2.0 , and 2.7 , respectively (Table 4 ).

The years during which the mean deterioration level of the same stake group reached 2.5, was also calculated 


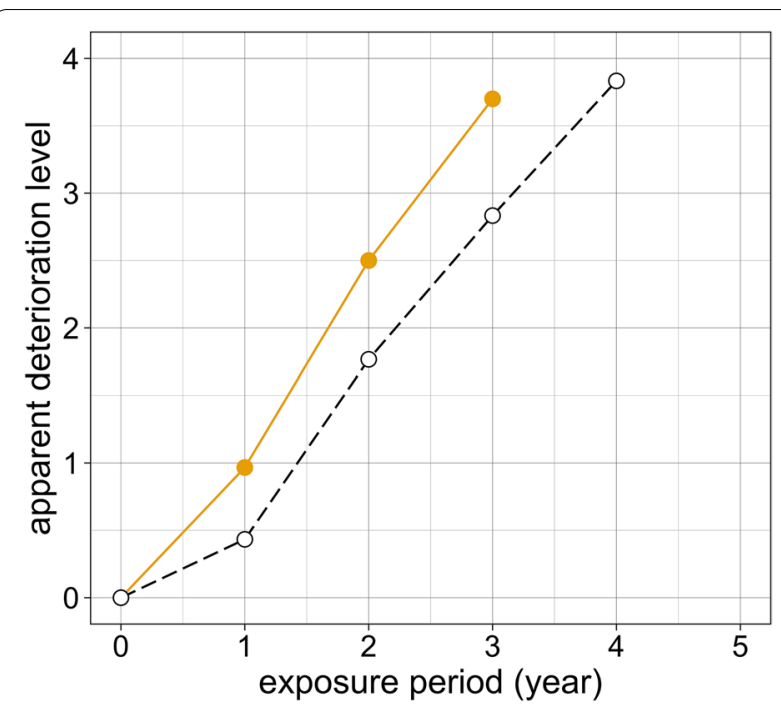

Fig. 3 Plot of deterioration level against exposure period. Closed circle; Ced-S, open circle; Ced-H

Table 4 Service life evaluated by the conventional method

\begin{tabular}{lllll}
\hline Abbreviations & \multicolumn{2}{l}{ Name of test site } & All sites \\
\cline { 2 - 4 } & Ibaraki & Nara & Toyama & \\
\hline Ced-S & 1.5 & 2.0 & 3.3 & 2.0 \\
Ced-H & 3.0 & 2.2 & 3.3 & 2.7 \\
Cyp-H & 3.1 & 2.5 & 3.2 & 2.8 \\
Lar-H & 2.8 & 2.4 & 3.8 & 2.8 \\
All species & 2.4 & 2.3 & 3.3 & 2.6 \\
\hline
\end{tabular}

according to Eq. (1). A summary of service life determined by each group and site is presented in Table 4 . The service life of the stakes ranged from 1.5 (Ced-S-I) to 3.8 (Lar-H-T). From the conventional calculation results, it appears that the wood deterioration rate is the highest and lowest at the Nara and Toyama sites, respectively. Contrastingly, in terms of the tree species and position, Ced-S appears to have the lowest durability, while Ced$\mathrm{H}, \mathrm{Cyp}-\mathrm{H}$, and Lar-H appear to have high durability. This result is common because it is accepted that sapwood shows lower durability than heartwood [28].

The service life determination by the conventional method is simple and useful; however, there remains mathematical ambiguity in the calculation process. The point of ambiguity derives from misuse of the ordinal scale. As shown in Table 3, the deterioration levels in JIS K 1571 [17] are designated from 0 to 5 according to the stake conditions. It is noteworthy that the values have a nonlinear relation and cannot be calculated in the same way as that using the proportional scale. It is mathematically inaccurate to calculate the mean of the deterioration levels collected by annual observation using the ordinal scale. Therefore, it is also incorrect to discuss differences in durability from apparent mean values calculated by the conventional procedure.

\section{Service life calculation by survival analysis}

To overcome the above ambiguity, survival analysis was adopted to address the differences in the service lives of the stake groups. In contrast to the conventional methods, the mathematical ambiguities in the stake tests can be diminished by applying survival analysis because it handles the proportional scale, that is, the time when the specific incidents occur. Therefore, the data can be used for further mathematical calculations without ambiguity. Additionally, survival analysis, such as the Kaplan-Meier method, has an added advantage as it can handle missing data. Incidentally, some stakes were lost after a long exposure period, and in other stakes, the bottom was lost because a rupture occurred in the stake at the ground level. In such cases, the KaplanMeier method can treat the lost data as censored data and draw a survival curve with mathematical rigidness.

The Kaplan-Meier method was used to compare the wood durability, for which the selection of the event was important. We defined the event as the time at which the stake deterioration level was 2.5. According to JIS K 1571 [17], the deterioration level is evaluated using integer values from 0 to 5 . Therefore, the timing was estimated from the last year that the deterioration level was below 2.5, and the first year that the deterioration level was above 2.5, according to Eq. (1).

The Kaplan-Meier curves for the cedar stakes tested at the three sites are shown in Fig. 4. The Y-axis indicates the survival probability, which is the ratio of stakes that did not reach the deterioration level of 2.5. The first sapwood stake (Ced-S) to reach the deterioration level of 2.5 was after a 10-month exposure, and half of the stakes reached the deterioration level of 2.5 in 2.2 years (Fig. 4). In the case of $\mathrm{Ced}-\mathrm{H}$, deterioration of the first stake appeared after 1.25 years of exposure, and it took 2.5 years for half of the stakes to reach the deterioration level of 2.5. The Peto \& Peto modification of the Gehan-Wilcoxon test revealed a significant difference between the durability of Ced-H and Ced-S $(p=0.0061)$.

Figure 4 shows another advantage of survival analysis. A tick mark appears on the Ced-S data (dashed line) after the 4-year exposure; this indicates that one stake was lost before it reached the deterioration level of 2.5. Survival analysis was developed to handle data sets containing lost data (censored data). 


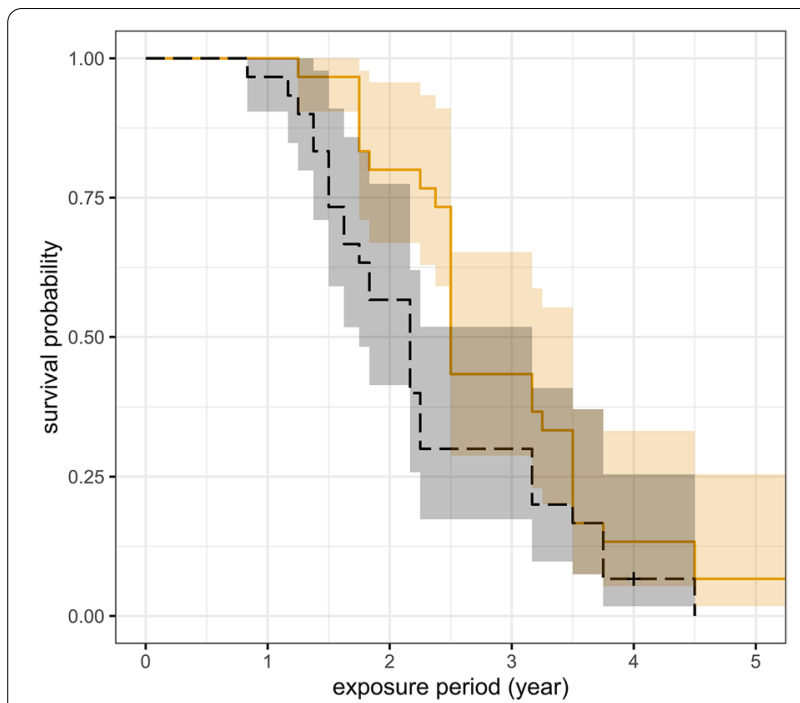

Fig. 4 Kaplan-Meier curves observed in Ced-S and Ced-H deterioration. Dashed line; Ced-S, solid line; Ced-H. Color-coded areas indicate $95 \%$ confidence intervals

\section{Effect of test site on the Ced-S and Ced-H service lives}

Since it was revealed that there was a significant difference between the service lives of Ced-S and Ced-H, we also compared their Kaplan-Meier curves among the three sites and found different characteristics (Fig. 5). At the Ibaraki site, Ced-S quickly reached a 2.5 deterioration level. However, Ced-H required more than 1.5 times longer than Ced-S to reach the 2.5 deterioration level. Contrastingly, Ced-S and Ced-H tested at the

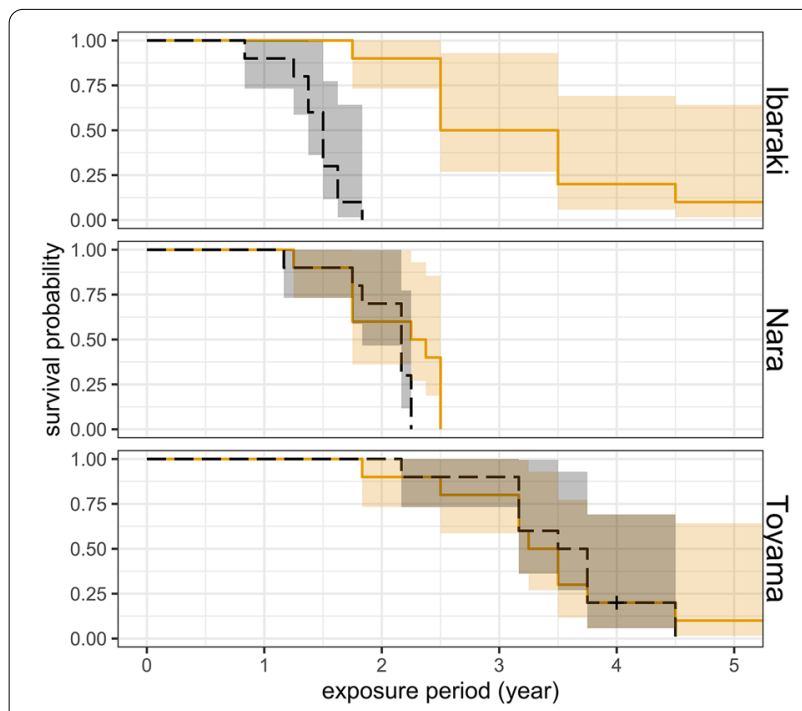

Fig. 5 Kaplan-Meier curves observed in Ced-S and $\mathrm{Ced}-\mathrm{H}$ deterioration at different sites. Dashed line; Ced-S, solid line; $\mathrm{Ced}-\mathrm{H}$. Color-coded areas indicate 95\% confidence intervals
Nara and Toyama sites showed similar Kaplan-Meier curves. Therefore, there may be no significant difference between the service lives of Ced-S and Ced-H. To reveal a significant difference between their service lives in the Nara and Toyama sites, Peto \& Peto modification of the Gehan-Wilcoxon test was carried out using the Holm's $p$ adjustment method. The results shown in Table 5 reveal that there are no significant differences between Ced$\mathrm{H}-\mathrm{N}$ and Ced-S-N and between Ced-H-T and Ced-S-T. Although it is accepted that the durability of Ced-H is higher than that of Ced-S, Fig. 5 and Table 5 indicate that this relationship does not apply to all cases. The former conventional field test carried out at the Nara site showed that deterioration of the Ced-S stake proceeds faster than that of the Ced-H stake $[29,30]$. The difference between the former studies and this work may be due to the stake origin. The former study used logs from Nara Prefecture. The survival analysis applied to estimate the effects of logging prefectures on natural durability will be the focus of our subsequent study.

\section{Effect of test site on the service lives of all stakes}

As discussed above, the testing sites affect the Ced-H and Ced-S service lives. Therefore, it is assumed that there is a significant difference in the wood deterioration rates among the three sites. To test this hypothesis, the survival curves of all stakes at the three sites were plotted (Fig. 6). The results indicate that the survival probability at the Nara site decreased the most quickly, whereas the slowest decrease was observed at the Toyama site. To estimate whether the difference in the survival curves is significant, the test was carried out in the same way as described in the previous section, and a significant difference was revealed between the Toyama site and the other two sites (Table 6).

It is unclear what causes this difference; however, the soil characteristics may be influential in causing this difference. The soil types at the Ibaraki, Nara, and Toyama sites are andosol, gleysol, and sandy-loam, respectively (Table 1 ). Among the three sites, the soil of the Toyama site may contain insufficient nutrients and water, which slows wood deterioration caused by wood-decaying microorganisms. Further research on

Table 5 Adjusted $p$ value between each stake group

\begin{tabular}{lccccc}
\hline Abbreviation & Ced-S-I & Ced-S-N & Ced-S-T & Ced-H-I & Ced-H-N \\
\hline Ced-S-N & 0.010 & - & - & - & - \\
Ced-S-T & 0.000 & 0.003 & - & - & - \\
Ced-H-I & 0.001 & 0.007 & 1.000 & - & - \\
Ced-H-N & 0.012 & 1.000 & 0.004 & 0.028 & - \\
Ced-H-T & 0.000 & 0.006 & 1.000 & 1.000 & 0.007 \\
\hline
\end{tabular}




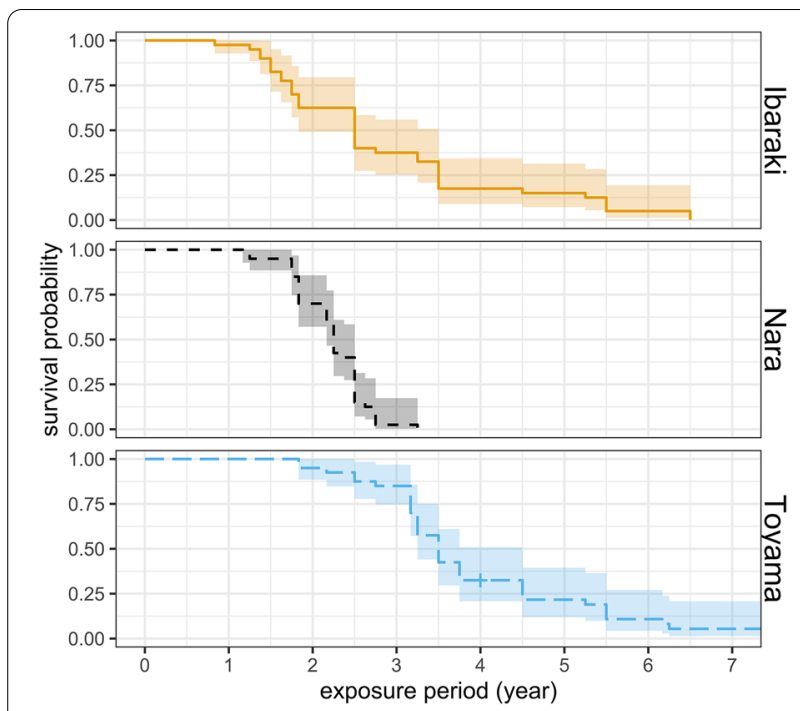

Fig. 6 Kaplan-Meier curves observed for deterioration of all stakes at different sites. Color-coded areas indicate $95 \%$ confidence intervals

Table 6 Adjusted $p$ value between each site

\begin{tabular}{llc}
\hline Site & lbaraki & Nara \\
\hline Nara & 0.138 & - \\
Toyama & 0.006 & 0.000 \\
\hline
\end{tabular}

microorganisms is required since soil and air conditions influence their survival on the stake [31].

\section{Effect of species on service life}

Besides the differences in heartwood and sapwood, wood durability is also known to vary with species. For example, the Housing Quality Assurance Act considers that Cyp-H is more durable than Ced-H and Lar-H and allows Cyp- $\mathrm{H}$ to be used as a sill member without wood preservation [32]. To verify the order of durability among the three species, survival analysis was applied to the Ced-H, Cyp-H, and Lar-H data at the three sites. The results shown in Fig. 7 suggest that the heartwood of the three species show similar Kaplan-Meier curves. Therefore, there is no significant difference among Cyp$\mathrm{H}$, Ced-H, and Lar-H. To confirm this relationship, a significance test was carried out according to the Peto \& Peto modification of the Gehan-Wilcoxon test with the Holm's $p$ adjustment method. The results that all $p$ values are higher than 0.8 , suggest that there is no significant difference among the durability of heartwood in the three specimens (Table 7). To investigate the order of durability among the three species, further research is needed.

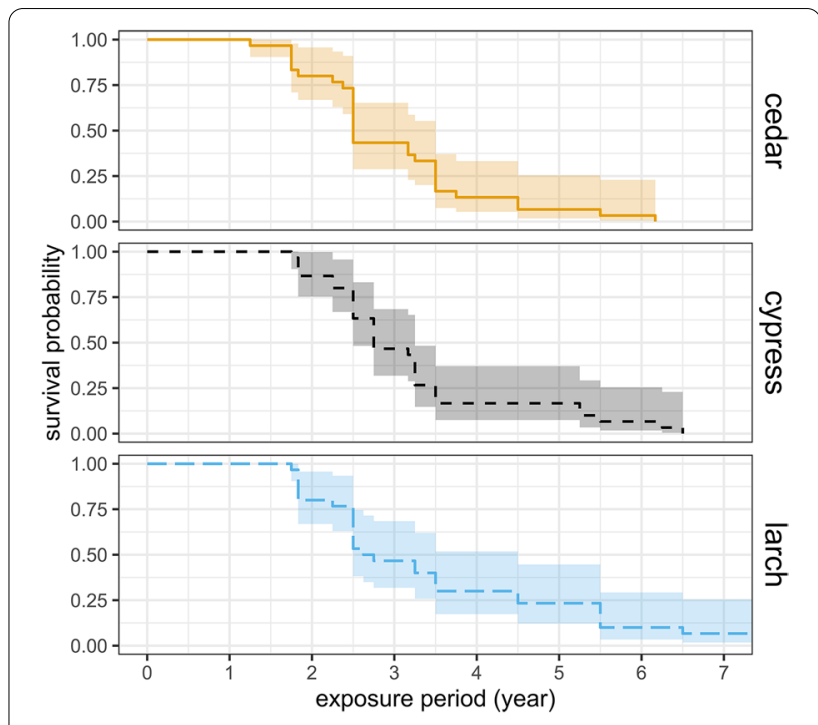

Fig. 7 Kaplan-Meier curves observed in the deterioration of heartwood at the three sites. Color-coded areas indicate 95\% confidence intervals.

Table 7 Adjusted $p$ value between each species

\begin{tabular}{llc}
\hline Species & Ced-H & Cyp-H \\
\hline Cyp-H & 0.83 & - \\
Lar-H & 0.83 & 0.87 \\
\hline
\end{tabular}

\section{Conclusion}

We developed a conventional stake test by adding a survival analysis to the conventional method.

The Kaplan-Meier curve is useful for estimating the stake group durability. Furthermore, it is useful for groups containing censored data, namely, lost data.

The durability difference among the stake groups can be calculated by the modified Gehan-Wilcoxon test with the Holm's $p$ adjusted with scientific collectiveness.

\section{Abbreviations}

Ced-S: Japanese cedar sapwood; Ced-H: Japanese cedar heartwood; Cyp-H: Japanese cypress heartwood; Lar-H: Japanese larch heartwood; I: Ibaraki site; $\mathrm{N}$ : Nara site; T: Toyama site.

\section{Acknowledgements}

Part of this study was funded by the Japan Wood Preservers Industry Association. We thank members of the technical committee at the JWPA for their help with this work. We are also grateful to the staff of the Forestry and Forest Products Research Institute (Ibaraki site), Nara Forest Research Institute (Nara site), and Forest Products Research Institute (Toyama site) for their help in inspecting the stakes.

\section{Authors' contributions}

All authors contributed to making the research plan through the study. IM mainly contributed to perform the survival analysis and write the manuscript. HS, HK, and WO contributed to conduct the stake test and to revise 
the manuscript. TK, TS contributed to prepare the stakes and manage the research. YI managed the research. All authors read and approved the final manuscript.

\section{Funding}

A part of this work was supported by the Japan Wood Preservers Industry Association.

\section{Availability of data and materials}

The data sets analyzed during the current study are available from the corresponding author upon reasonable request.

\section{Declarations}

\section{Competing interests}

The authors declare that they have no competing interests.

\begin{abstract}
Author details
${ }^{1}$ Kansai Research Center, Forestry and Forest Products Research Institute, Fusimiku, Kyoto 612-0855, Japan. ${ }^{2}$ Nara Forest Research Institute, Takatori, Takaichi-gun, Nara 635-0133, Japan. ${ }^{3}$ Toyama Forest Products Research Institute, Kurokawa, Imizu 939-0311, Japan. ${ }^{4}$ Forestry and Forest Products Research Institute, Matsunosato, Tsukuba 305-8687, Japan. ${ }^{5}$ Kanematsu Sustec Corporation, Ohtakanomori, Nagareyama 270-0128, Japan. ${ }^{6}$ The Japan Wood Preservers Industry Association, Akasaka, Minatoku 107-0052, Japan. ${ }^{7}$ Architectural Research Association, Sakyoku, Kyoto 606-8203, Japan.
\end{abstract}

Received: 26 April 2021 Accepted: 30 May 2021

Published online: 08 June 2021

\section{References}

1. IPCC (2014) Climate change 2014, fifth assessment report, mitigation of climate change. Cambridge University Press, New York

2. Soimakallio S, Saikku L, Valsta L, Pingoud K (2016) Climate change mitigation challenge for wood utilization the case of Finland. Environ Sci Technol 50(10):5127-5134

3. Leskinen P, Cardellini G, González-García S, Hurmekoski E, Sathre R, Seppälä J, Smyth C, Stern T, Verkerk PJ (2018) Substitution effects of woodbased products in climate change mitigation From Science to Policy 7. Eur Forest Institute. https://doi.org/10.36333/fs07

4. Noda R, Kayo C, Sasaki T, Takaoku S (2014) Evaluation of CO 2 emissions reductions by timber check dams and their economic effectiveness. J Wood Sci 60(6):461-472

5. Noda R, Kayo C, Yamanouchi M, Shibata N (2016) Life cycle greenhouse gas emission of wooden guardrails: a study in Nagano Prefecture. J Wood Sci 62(2):181-193

6. Kayo C, Noda R (2018) Climate change mitigation potential of wood use in civil engineering in Japan based on life-cycle assessment. Sustainability 10(2):561

7. Brandner R, Flatscher G, Ringhofer A, Schickhofer G, Thiel A (2016) Cross laminated timber (CLT): overview and development. Eur J Wood Wood Prod 74(3):331-351

8. Derikvand M, Jiao H, Kotlarewski N, Lee M, Chan A, Nolan G (2019) Bending performance of nail-laminated timber constructed of fast-grown plantation eucalypt. Eur J Wood Wood Prod 77(3):421-437

9. Sotayo A, Bradley D, Namari S, Bathera M, Sareha P, Oudjeneb M, ElHoujeyrib E, Hartec A, Mehrac S, O'Ceallaighc C, Hallerd P, Namarid S, Makradie A, Belouettare S, Bouhalae L, Deneufbourgf F, Guan Z (2020) Review of state of the art of dowel laminated timber members and densified wood materials as sustainable engineered wood products for construction and building applications. Dev Built Environ 1:100004

10. Preston AF (2000) Wood preservation. Forest Prod J 50(9):12-19
11. Richardson BA (2002) Wood preservation. E\& FN Spon, London

12. Esteves B, Pereira H (2009) Wood modification by heat treatment: A review. BioResources 4(1):370-404

13. Salminen $E$, Valo R, Korhonen M, Jernlås R (2014) Wood preservation with chemicals: Best Available Techniques (BAT). https://www.ippc.int/static/ media/files/publications/en/2014/09/04/17_ewgwoodhandicrafts_ 2014_sep.pdf. Accessed 1 Apr 2021

14. Gérardin P (2016) New alternatives for wood preservation based on thermal and chemical modification of wood-a review. Ann Forest Sci 73(3):559-570

15. Teng TJ, Arip MNM, Sudesh K, Nemoikina A, Jalaludin Z, Ng EP, Lee HL (2018) Conventional technology and nanotechnology in wood preservation: a review. BioResources 13(4):9220-9252

16. E10-16 (2020) Laboratory method for evaluating the decay resistance of wood-based materials against pure basidiomycete cultures: soil/block test. American Wood Protection Association, USA

17. JIS K 1571 (2010) Test methods for determining the effectiveness of wood preservatives and their performance requirements. Japanese Industry Standards Committee, Japan

18. BS EN 599-1:2009+A1 (2013) Durability of wood and wood-based products. Efficacy of preventive wood preservatives as determined by biological tests Specification according to use class, British Standards Institution, UK

19. E7-15 (2020) Standard field test for evaluation of wood preservatives to be used in ground contact (UC4A, UC4B, UC4C); Stake Test. Wood Protection Association, USA

20. E14-16 (2020) Laboratory method for rapidly evaluating the decay resistance of wood-based materials in ground contact: soil bed test. Wood Protection Association, USA

21. International Research Group on Wood Protection (2019) https://www. irg-wp.com. Accessed 1 Apr 2021

22. Kleinbaum DG, Klein M (2010) Survival analysis. Springer, New York

23. Geospatial Information Authority of Japan. https://www.gsi.go.jp/. Accessed 1 Apr 2021

24. Japan Meteorological Agency. https://www.data.jma.go.jp/gmd/cpd/cgibin/view/index.php. Accessed 1 Apr 2021

25. The digital soil map of Japan. (2017) https://soil-inventory.dc.affrc.go.jp/. Accessed 1 Apr 2021

26. R Core Team (2016). R: A language and environment for statistical computing. R Foundation for Statistical Computing, Vienna, Austria. https:// www.R-project.org/. Accessed 1 Apr 2021

27. Therneau TM, Lumley T, Elizabeth A, Cynthia C (2021) Package 'survival'. https://cran.r-project.org/web/packages/survival/survival.pdf. Accessed 1 Apr 2021

28. Clausen CA (2010) Biodeterioration of Wood. In: Forest Products Laboratory (ed). Wood Handbook (Centennial Edition), chapter 14, Madison: Department of Agriculture Forest Service. https://www.fpl.fs.fed.us/ documnts/fplgtr/fpl_gtr190.pdf

29. Sakai H, Iwamoto N (2000) Field test. In: Nara Forest Research Institute (ed). Wood Processing Technology Handbook (Revised Edition). Takaichigun: Nara Forest Research Institute, pp.292-299 (in Japanese)

30. Teranishi Y, Sakai H, Minamimoto A (2013) Bioresistance of sugi heartwood dried by combination of high-frequency heating and hot air heating: the comparison between field test and laboratory test. Wood Industry 68(7):301-304 (in Japanese)

31. Ishiyama N, Horisawa S, Hara T, Momohara YM, I, (2021) Microbiological community structure on logs used for groynes in a riverbank system. J Wood Sci 67:11

32. Housing Quality Assurance Act (1999) Law number: Act No. 81 of 1999 (in Japanese)

\section{Publisher's Note}

Springer Nature remains neutral with regard to jurisdictional claims in published maps and institutional affiliations. 